
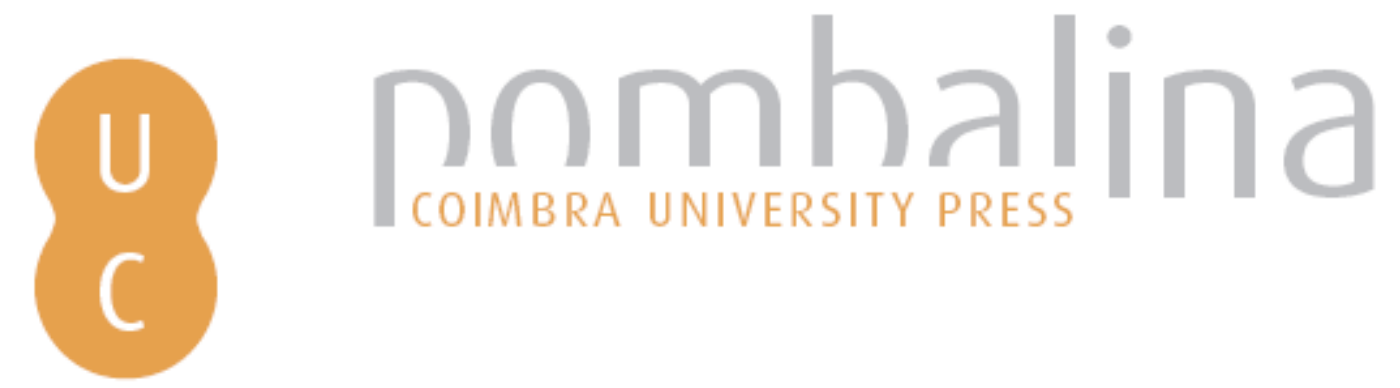

\title{
De Alberti aos CIAM: em Direção a uma Abordagem humanista do ensino da Arquitetura e do habitat
}

Autor(es): $\quad$ Moniz, Gonçalo Canto; Mota, Nelson

Publicado por: Imprensa da Universidade de Coimbra

URL

persistente: URI:http://hdl.handle.net/10316.2/36681

DOI: $\quad$ DOI:http://dx.doi.org/10.14195/978-989-26-1015-3_19

Accessed : $\quad$ 26-Apr-2023 09:57:34

A navegação consulta e descarregamento dos títulos inseridos nas Bibliotecas Digitais UC Digitalis, UC Pombalina e UC Impactum, pressupõem a aceitação plena e sem reservas dos Termos e Condições de Uso destas Bibliotecas Digitais, disponíveis em https://digitalis.uc.pt/pt-pt/termos.

Conforme exposto nos referidos Termos e Condições de Uso, o descarregamento de títulos de acesso restrito requer uma licença válida de autorização devendo o utilizador aceder ao(s) documento(s) a partir de um endereço de IP da instituição detentora da supramencionada licença.

Ao utilizador é apenas permitido o descarregamento para uso pessoal, pelo que o emprego do(s) título(s) descarregado(s) para outro fim, designadamente comercial, carece de autorização do respetivo autor ou editor da obra.

Na medida em que todas as obras da UC Digitalis se encontram protegidas pelo Código do Direito de Autor e Direitos Conexos e demais legislação aplicável, toda a cópia, parcial ou total, deste documento, nos casos em que é legalmente admitida, deverá conter ou fazer-se acompanhar por este aviso.

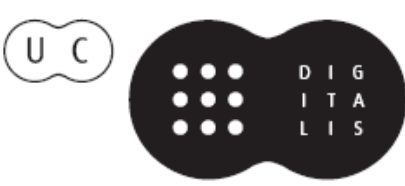


IMPRENSA DA

UNIVERSIDADE

DE COIMBRA

COIMBRA

UNIVERSITY

PRESS

\section{NA GÉNESE DAS RACIONALIDADES MODERNAS II}

Em torno de Alberti e do Humanismo

MÁRIO KRÜGER et alii

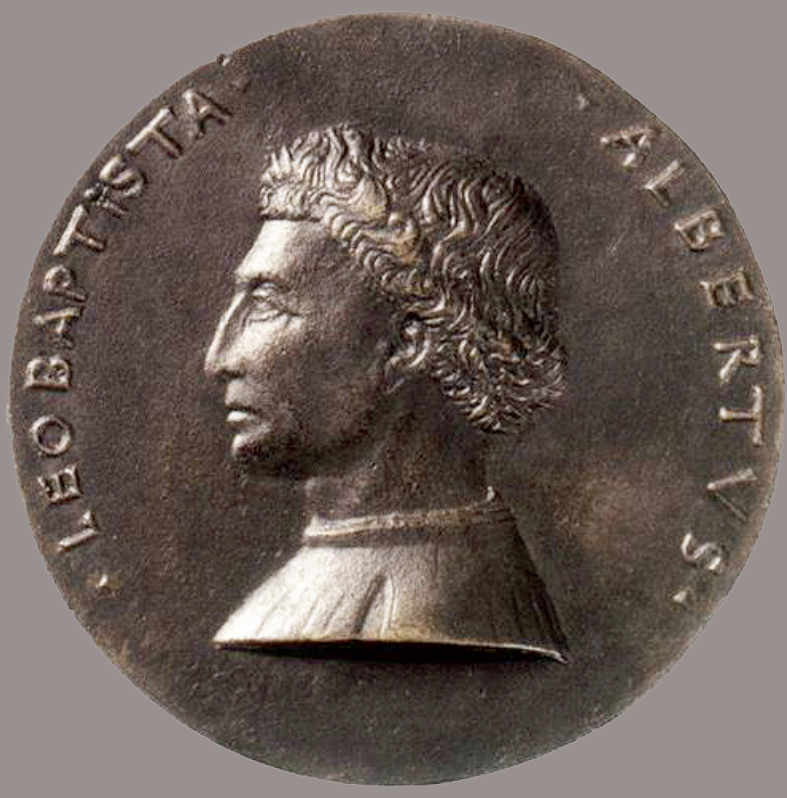




\section{DE ALBERTI AOS CIAM : EM DIREÇÃOA UMA ABORDAGEM HUMANISTA DO ENSINO DA ARQUITETURA E DO HABITAT}

Gonçalo Canto Moniz, Nelson Mota

\section{Resumo}

No final da década de 1940, a obra e o pensamento de Leon Battista Alberti são revisitados por uma nova geração de arquitetos e historiadores que pretendem repensar a arquitetura moderna a partir da sua relação com o Homem. Esta geração envolve-se num debate sobre a arquitetura onde se exploram outros caminhos na procura de uma abordagem disciplinar mais humanista, suportada por um novo paradigma, o humanismo moderno.

Num primeiro momento, este artigo pretende identificar a origem desta nova abordagem, nomeadamente a partir de uma leitura crítica a uma obra chave, o livro Architectural Principles in the Age of Humanism, publicado em 1949 pelo historiador de arte Rudolf Wittkower (1901-1971). Num segundo momento, interessa analisar o impacto que o humanismo moderno teve nos debates internacionais sobre arquitetura na década de 1950, concretamente nos CIAM e na fundação do grupo que viria a ser conhecido como TEAM 10, tanto na construção de um ensino humanista como de uma arquitetura humanista. Num terceiro momento, verifica-se que este debate teve também desdobramentos na Escola Superior de Belas Artes do Porto, através da ação dos seus jovens docentes, tanto na prática pedagógica, como na prática profissional. Deste modo, pode-se estabelecer uma ponte entre o humanismo 
albertiano e a construção de uma forma de pensar, de ensinar e de fazer arquitetura na Escola do Porto, que foi fundamentalmente protagonizada por Fernando Távora e Octávio Lixa Filgueiras.

Arquitetura; Alberti; Humanismo; CIAM; Escola do Porto

\section{Résumé}

À la fin des années 1940, le travail et la pensée de Leon Battista Alberti sont revisités par une nouvelle génération d'architectes et d'historiens qui souhaitent repenser l'architecture moderne de sa relation avec l'homme. Cette génération prend part à un débat sur l'architecture où s'explorent d'autres chemins à la recherche d'une approche plus humaniste de la discipline, soutenue par un nouveau paradigme, l'humanisme moderne.

Initialement cet article est d'identifier l'origine de cette nouvelle approche, en particulier à partir d'une lecture critique d'un ouvrage clé, Architectural Principles in the Age of Humanism, publié en 1949 par l'historien d'art Rudolf Wittkower (1901-1971 ). Deuxièmement, il est intéressant d'analyser l'impact que l'humanisme moderne avait dans les discussions internationales sur l'architecture dans les années 1950, en particulier dans le CIAM et dans la fondation du groupre Team 10, à la fois dans la construction d'une éducation humaniste comme d'une architecture humaniste. Troisièmement, il semble que ce débat a également eu des répercussions à l'École des Beaux-Arts de Porto, par l'action de leurs jeunes enseignants, tant dans la pratique de l'enseignement, comme dans la pratique professionnelle. Ainsi, on peut établir un pont entre l'humanisme albertienne et la construction d'une façon de penser, d'enseigner et de faire de l'architecture à l'École de Porto, qui a été principalement réalisée par Fernando Távora et Octavio Lixa Filgueiras. Architecture; Humanisme; Alberti; CIAM; École de Porto

\section{Abstract}

In the late 1940s, Leon Battista Alberti's work and thinking were reconceptualised by a new generation of architects and historians 
that aimed at reconciling Man and modern architecture. Indeed, this generation triggered an architectural debate that pursued a more humanistic approach to architecture, supported by a new paradigm, modern humanism.

The first part of this article aims at identifying the background against which this new approach came about, through a critical review of a key work, the book Architectural Principles in the Age of Humanism, published in 1949 by the art historian Rudolf Wittkower (1901-1971). Then, the article discusses the extent to which the idea of modern humanism influenced the international architectural debate in the 1950s on architectural education and design, especially in post-war CIAM and in the outset of Team 10. Finally the article examines the impact of this debate in Porto's School of Fine Arts, through the performance of its young teachers, both in their educational approach as well as in their professional practice. The article concludes that there is a bridge between Alberti's humanism and the construction of a new way of architectural thinking, teaching and designing at the School of Porto, which was chiefly built up by Fernando Távora and Octávio Lixa Filgueiras through their interpretations of the idea of modern humanism.

Architecture; Humanism; Alberti; CIAM; School of Porto 


\section{De re aedificatoria e o movimento moderno}

O discurso albertiano, nomeadamente aquele que fixou no De re aedificatoria, construiu um novo paradigma arquitetónico sobre os escombros da Idade Média. Pretendia edificar um mundo novo, ordenado e racional, a partir dos elementos da Antiguidade clássica. Este novo mundo destinava-se também a um homem novo. Em meados do século $\mathrm{XX}$, numa época de crise política mas também disciplinar, o legado albertiano foi recuperado com o objetivo de refundar a arquitetura e a cidade, mas principalmente com o objetivo de reestabelecer a relação entre a arquitetura e o homem. O fim da $2^{a}$ Guerra Mundial gerou precisamente esta vontade de recolocar o problema da arquitetura e da própria sociedade. Neste contexto, assiste-se a uma reforma das instituições, do pensamento hegemónico e, claro, da arquitetura. Se as Nações Unidas redigem a Carta dos Direitos Humanos (1948), na arquitetura multiplicam-se as Declarações que exigem uma nova forma de pensar e de agir - nos CIAM (Congressos Internacionais de Arquitetura Moderna), no Congresso Nacional dos Arquitetos (1948) ou mesmo nas Escolas de Arquitetura, tanto portuguesas como internacionais.

A reorientação dos CIAM a partir de 1947, no CIAM VI, o primeiro depois da guerra, espelha esta vontade de reformular os postulados do movimento moderno, nomeadamente da sua própria Carta de Atenas (1933). É neste espaço de debate que se encontram os arquitetos portugueses da nova geração, entre eles Fernando Távora, com os seus congéneres ingleses, holandeses e italianos, com particular destaque para Peter e Alison Smithson, Aldo van Eyck, Giancarlo de Carlo. Esta nova geração irá questionar alguns dos princípios fundadores dos CIAM e fundar um novo grupo, o TEAM 10, empenhado numa abordagem mais humanista da arquitetura, bem patente no manifesto de Doorn e significativamente influenciada pelo livro que retoma explicitamente o pensamento albertiano para a contemporaneidade: Architectural Principles in the Age of Humanism (1949) de Rudolf Wittkower. O processo de humanização da arquitetura moderna no final dos anos 40 desenvolve-se em diversos palcos, mas é nos CIAM que as diversas perspetivas se confrontam, nomeadamente a portuguesa e a inglesa. 


\section{O regresso ao humanismo}

A presença do discurso albertiano no debate moderno, da arquitetura moderna, é pontual e acontece principalmente no final da década de 40 com o regresso aos clássicos para reencontrar os fundamentos da arquitetura.

É claro, que podemos associar aspetos do discurso moderno ao discurso de Alberti, como sugere Mário Krüger através de Le Corbusier, mas só com Wittkower e Colin Rowe se aposta efetivamente no regresso de Alberti, de Palladio e mesmo de Vitrúvio. De fato, é na segunda metade do século XX que, ainda segundo Krüger, se concentram a grande maioria das traduções da obra de Alberti, nomeadamente em inglês, 1955; em checo, 1956; em polaco, 1960; em italiano e latim, $1966^{520}$.

De fato, a influência do texto fundacional de Alberti, De re aedificatoria, foi precedida pela publicação, em 1949, do livro de Rudolf Wittkower com o título Architectural Principles in the Age of Humanism e do texto do seu discípulo, Collin Rowe, The Mathematics of the Ideal Villa (1947), ambos investigadores do Warburg Institute. O texto de Wittkover conquista a atenção dos arquitetos, tanto dos profissionais como dos diletantes e principalmente dos mais jovens, que veem aqui a possibilidade de renovação da arquitetura moderna e um contributo para a redefinição dos princípios arquitetónicos. Atestando este interesse, numa carta para o editor do RIBA Journal publicada em fevereiro de 1952, Alison e Peter Smithson escreviam que o "Dr. Wittkower is regarded by the younger architects as the only art-historian working in England capable of describing and analysing buildings in spatial and plastic terms, and not in terms of derivations and dates" 521 .

520 Cf. MÁRIO KRÜGER, "A Receção ao Da Arte Edificatória”, em Leon Battista Alberti, Da Arte Edificatória, Lisboa, Fundação Calouste Gulbenkian, 2011, pp. 75-129

521 ALISON SMITHSON \& PETER SMITHSON, "Correspondance: Architectural Principles in the Age of Humanism", em The Journal of the Royal Institute of British Architects, n. ${ }^{\circ}$ 59(4), 1952, p.1. 


\section{Charte de l'Habitat: "A cidade é uma casa em ponto grande"}

No final de janeiro de 1954 , seis jovens membros dos grupos CIAM Holandês e Inglês encontraram-se em Doorn, na Holanda. Neste encontro, foi elaborado o famoso Manifesto de Doorn, onde esta nova geração de membros do CIAM criticava os seus "pais espirituais", Le Corbusier, Gropius e Giedion. Estavam especialmente interessados em sublinhar a inadequação dos princípios da Carta de Atenas, argumentando que "Urbanism considered and developed in the terms of the Charte d'Athene [sic] tends to produce 'towns' in which vital human associations are inadequately expressed." 522

O grupo era explicitamente contra a ideia de uma avaliação do ambiente construído através da lógica das quatro funções propostas na Carta de Atenas, que não considerava outros "campos ecológicos" para além de cidades. Em vez do determinismo funcional, eles argumentaram que era necessário ter em consideração a comunidade como um todo, independentemente do seu tamanho. Cada comunidade deveria ser vista como um "complexo total e único". O resultado desta nova abordagem metodológica foi a definição do conceito de "escalas de associação", inspirada pela "Valley Section", um esquema proposto no início do século XX pelo sociólogo Patrick Geddes. 523

Uma das consequências mais marcantes desta proposta, foi uma mudança deliberada de uma abordagem universalista, a Carta de Atenas, para uma outra mais preocupada com a "atmosfera" específica, como Peter Smithson lhe chamava, que deveria ser a base para a criação da Charte de l'Habitat. Este grupo de jovens membros dos CIAM também criticavam a separação entre arquitetura e planeamento urbano, que tinha sido incorporada no discurso entre guerras do CIAM. "In the past of CIAM", Smithson argumenta, "[there was] too much dualism between

522 AA.VV., Statement on Habitat, em Doorn Meeting. Doorn. 1954. NAi - BAKEg26

523 Para mais informação sobre Patrick Geddes e o Team 10 Cf. V.M. WELTER, "In-between space and society. On some British roots of Team 10's urban thought in the 1950s", em Max Risselada \& Dirk van den Heuvel, eds. Team 10 1953-81. In search of a Utopia of the present. Rotterdam, NAi Publishers, 2005, pp. 258-263. 
house and city, without realising the interrelation" 524 . Peter Smithson foi, juntamente com seus futuros companheiros do TEAM 10, chamando a atenção para uma nova compreensão da disciplina, que deveria ser apoiada pela ideia de relacionamento entre as diversas componentes do ambiente construído. Esta abordagem evoca a famosa frase de Alberti, já sugerida por Platão, que estabelece que "a cidade é uma casa em ponto grande e, inversamente, a casa é uma cidade em ponto pequeno" 525 , trazendo desta forma, na década de 1950, uma importante contribuição para uma mudança de paradigma disciplinar.

\section{A influência de Alberti no CIAM e no Team 10}

Alguns anos depois, em dezembro de 1954, no texto com as instruções para os grupos nacionais para as comunicações a apresentar no congresso CIAM 10, a Comissão Organizadora pediu que os grupos apresentem os seus projetos para um habitat humano ideal, "reconhecendo e explorando a realidade da suas várias situações”. Estes projetos deverão ser apresentados de acordo com as escalas de associação inspiradas na Valley Section de Geddes, "Metrópole", "Cidade", "Aldeia", e "Campo", que são também conhecidas como "símbolos de uma série muito mais complexa de relacionamento."526

Tanto a ideia das escalas de associação, como a atenção à circunstância particular, acarinhados neste momento pela geração mais jovem, tem eco numa parte do De re aedificatoria de Alberti. Este aspeto, contudo, foi ignorado por Wittkower. No entanto, o paralelismo entre o humanismo de Alberti e a tentativa de encontrar na década de 1950 uma alternativa para a abordagem mecanicista da ortodoxia moderna no período de entre-guerras, parece-nos merecedora de mais atenção. No seu tratado, Alberti define claramente que "a edificação consta de seis partes, a saber:

524 AA.VV. Notes from first meeting, em Team 10 Meeting, Door, 1954. NAi - TTEN7 525 LEON BATTISTA ALBERTI, Da Arte Edificatória, Lisboa, Fundação Calouste Gulbenkian, 2011, Livro I, cap. IX, p. 157. Introdução, notas e revisão disciplinar de Mário Krüger, tradução de Espírito Santo.

526 TEAM 10, Draft Framework 5 - CIAM X - Instructions to Groups. In CIAM 10, 1954. 
a região, a área, a compartimentação, a parede, a cobertura, a abertura" ${ }^{27}$. Assim, os elementos de que todo o edifício é composto são: regio (os arredores do edifício), a area (o local da construção), partitio (partição), paries (parede), tectum (telhado ) e Apertio (abertura).

Os descritores de Alberti para sistematizar as partes da edificação parecem estar visivelmente assumidos nos famosos 5 Points d'une Architecture Nouvelle, publicado originalmente por Le Corbusier e Pierre Jeanneret em $1927^{528}$. Na sua primeira publicação em alemão, Le Corbusier argumentou que esta "Nova Arquitetura" foi estabelecida contra a arquitetura do passado, alegando que "Il ne ici demeure plus rien des enseignements à la lettre des écoles", e que "Il ne rest, plus rien de l'architecture ancienne."529 Apesar deste confronto, tanto quanto sabemos, Le Corbusier nunca se referiu a Alberti como fonte ou referência para os seus manifestos e outros escritos. No entanto, com exceção do descritor regio (região) de Alberti, Le Corbusier e Pierre Jeanneret seguirão à risca os outros descritores de Alberti na formulação dos Points d'une Architecture Nouvelle ${ }^{530}$.

Contudo, o descritor de Alberti que não foi considerado por Le Corbusier e Jeanneret nos "5 Points", região, aparece mais tarde como a primeira cláusula de um outro importante manifesto, a Carta de Atenas. Neste texto podemos observar, mais uma vez, uma certa familiaridade entre o conceito empregue por Le Corbusier e o de Alberti. Na verdade, para o último, região era tanto atmosfera envolvente do edifício como os aspetos geográficos em torno do lugar, enquanto que para o primeiro, La Région era um "ensemble économique, social et politique."531

527 LEON BATTISTA ALBERTI, op.cit., Livro I, cap. IX, p. 147.

528 WERNER OECHSLIN, "5 Points d'une Architecture nouvelle”, em JAQUES LUCAN (ed.), Le Corbusier, une encyclopédie, Paris, Éditions du Centre Pompidou, Spadem, 1987, pp. 92-95

529 Estas frases foram reescritas na publicação de 1929 num tom mais suave: Cf. WERNER OECHSLIN, op.cit., p. 93.

530 Os pilotis de Le Corbusier são uma substituição da area de Alberti; a planta livre é uma resposta ao partitio; a fachada livre desafia o conceito de parie de Alberti; a ideia do terraço-jardim de Le Corbusier pode ser posta em paralelo com o tectum albertiano ainda que com uma abordagem distinta; e a janela "en longueur" relaciona-se com apertio. CF. MÁRIO KRÜGER, op.cit., pp. 110-113.

531 Cf. JOHN R. GOLD, "Creating the Charter of Athens: CIAM and the Functional City, 1933-43”. Em The Town Planning Review, n. ${ }^{\circ}$ 69, 1998, pp. 225-247. 
No início de 1950, direta ou indiretamente, Le Corbusier e Alberti viriam a ser novamente atores principais no debate disciplinar. De facto, na sua carta ao editor do RIBA Journal, os Smithsons também relatam que

"Dr. Giedion at a lecture at the I.C.A. earlier in the year stated that during 1950 at seminars both in Zurich and at the M.I.T. the most discussed books of the year were Le Modulor and The Architectural Principles of the Age of Humanism, both concerned with proportion. Dr. Wittkower was furthermore the only representative from this country invited to the recent International Congress on Proportion at Milan when mathematicians, artists and architects met to discuss this vital subject." 532

Assim, os Smithsons classificaram os sistemas de proporção como um "tema vital". Mais ainda, no mesmo número do RIBA Journal, John Voelcker, do grupo britânico dos CIAM, também refere a importância do livro de Wittkower. Ele afirma que "for many of our (younger) generation this application of number illuminates for a fleeting instant the immediate and, I speculate, the eternal quest for coherence and rapport in our actions, and more specifically in our building." E termina a sua carta citando a conferência de Wittkower em 1951 no congresso De Divina Proportioni,

"This examination of the purely historical (systems of proportion) can, I believe, give us a direction concerning our contemporary problems, the time of non-Euclidian geometry and of the fourth dimension. Our idea of time and space is, by necessity, different from that of past centuries, and there is no short cut to a new understanding of proportion. 533

Por isso, gostaríamos de sugerir que o conceito de Escalas da Associação proposto pelo TEAM 10, embora inspirado pela "Valley Section" de Patrick Geddes, também é tributário de uma negociação crítica dos

532 ALISON SMITHSON \& PETER SMITHSON, op.cit., p. 140.

533 JOHN VOELCKER, "Correspondence: Architectural Principles in the Age of Humanism", em The Journal of the Royal Institute of British Architects, n. ${ }^{\circ}$ 59, 1952, p.141. 
elementos de construção e dos sistemas de proporção de Alberti, com os "5 pontos" e a Carta de Atenas de Le Corbusier. Além disso, a ênfase sobre a ideia de relacionamento, destacado como um dos conceitos mais importantes que resultaram da reunião em Doorn, sugere uma reconcetualização da Carta de Atenas através de uma perspetiva que segue a ideia de Alberti que propõe "a cidade como uma casa em ponto grande e, inversamente, a casa como uma cidade em ponto pequeno". Esta reconcetualização explora também uma transição de um humanismo racional/intelectual enraizada na Antiguidade Clássica, de Platão em diante, para um humanismo físico/fenomenológico, emergente no rescaldo da Segunda Guerra Mundial.

Esta reconcetualização seria influente para o debate do pós-guerra sobre as questões da habitação e das políticas de identidade, que encontrou nos congressos CIAM um palco privilegiado através da eleição da ideia de "Habitat" como tema central das suas reuniões. A tensão entre essas duas manifestações diferentes de humanismo viria a ser sintetizado na participação de uma fação periférica do CIAM, o grupo Português. Assim, para ilustrar o resultado de tal debate, vamos analisar a sua participação nos congressos CIAM do pós-guerra, avaliando-o num contexto de mudança de metodologias no ensino de arquitetura e na definição da própria disciplina.

\section{CIAM Porto: formação social e humanista}

O grupo CIAM Português, conhecido por CIAM Porto, foi formado por um número relativamente pequeno de arquitetos reunidos em torno do grupo ODAM, Organização dos Arquitetos Modernos, criado em 1947, e da Escola de Belas Artes do Porto. Empenhados na luta pela defesa da arquitetura moderna, desde cedo se destacaram os arquitetos Mário Bonito, Arménio Losa e Alfredo Viana de Lima, sendo este o primeiro a frequentar os CIAM e a estabelecer contatos com Sigfried Giedion. Junto com Viana de Lima estavam também alguns jovens arquitetos e assistentes da Escola do Porto. Entre eles, dois acabariam por dar um contributo 
fundamental para o trabalho apresentado nos congressos CIAM: Fernando Távora e Octávio Lixa Filgueiras. 534

Estes jovens arquitetos incorporavam a mudança de paradigma que a formação do arquiteto na Escola do Porto estava a explorar no início de 1950. O líder desse processo foi o diretor da escola, Carlos Ramos, que, desde 1940, incentivava o "ensino coletivo" na cadeira de Arquitetura ${ }^{535}$. Ramos, promoveu a fusão de uma abordagem pedagógica humanista clássica com métodos pedagógicos modernos. Assim, nas suas aulas convergiam tanto o texto de Vitrúvio como as ideias de Walter Gropius. Por um lado, Carlos Ramos usa a definição vitruviana de Arquiteto para reforçar a relação entre a teoria e a prática, tal como Alberti inicia o seu tratado De re aedificatoria $^{536}$. Por outro lado, propõe o trabalho de equipa, o método de "aprender fazendo" (learning by doing) de John Dewey e a interrelação entre arquitetura, construção e cidade, acompanhando a pedagogia de Walter Gropius.

Carlos Ramos reconhece a sua proximidade com Gropius e traduz para português o manifesto "Training the Architect"537 escrito para a apresentação do arquiteto alemão em Harvard, e divulgado na Comissão de Educação dos CIAM entre 1949 e 1954538. Este texto seria, aliás, a base da desejada Carta de Educação promovida com Ernesto Rogers, que apenas foi debatida na reunião de abril de 1950 do Secretariado dos CIAM, realizado em Paris 539.

O próprio Rogers associa a ação de Gropius à atitude albertiana, que poderíamos ver também em Carlos Ramos, e escreve no seu famoso ensaio A Arquitetura depois da geração dos mestres, traduzido em 1961 por Sílvia Viana de Lima e publicado pelo ainda denominado grupo CIAM Porto.

534 Alfredo Viana de Lima (1913-1991); Fernando Távora (1923-2005); Octávio Lixa Filgueiras (1922-1996). O grupo CIAM-Portugal foi oficialmente criado em 1951, depois da participação de Viana de Lima e Távora congresso CIAM VIII de Hoddesdon.

535 CARLOS RAMOS, "Arquitetura. Algumas Palavras e o seu Verdadeiro Significado", em Sudoeste, n. ${ }^{\circ}$ 3, pp.36-37, 1935.

536 LEON BATTISTA ALBERTI, op.cit., p.138.

537 WALTER GROPIUS, “Training the Architect”, Twice a Year, n. ${ }^{\circ}$ 2, 1939, pp.142-151.

538 The Educational Committee funciona entre 1947 e 1953, desaparecendo no CIAM 10.

539 Cf. ANA TOSTÕES \& GONÇALO CANTO MONIZ (eds.), Docomomo Journal, Training the Architect, n. ${ }^{\circ} 49,2014$. 
"Gropius é a maior consciência do movimento moderno; é a nossa consciência; pedagogo, o seu rigor lógico analisa a problemática da arquitetura e sintetiza-a; é o criador de um método que vence os princípios 'a priori' dos estilos tradicionais e facilita-nos a compreensão das coisas, torna-nos capazes de atingir os problemas e dá lógica e harmonia à sua forma e espírito. Gropius é o Leon Battista Alberti da nossa época" 540 .

O apreço de Rogers pela abordagem pedagógica de Gropius evidencia a continuidade entre o humanismo de Alberti e o pensamento moderno que relaciona Ciência e Homem. Esta continuidade entre humanismo e modernidade, que podemos denominar de "humanismo moderno"541, é explorada também pela pedagogia de Carlos Ramos na Escola do Porto.

A proposta de Ramos será ampliada a toda a Escola com a sua nomeação para diretor, em 1952, e com a entrada de novos assistentes e ex-alunos, como Fernando Távora, em 1950, e Octávio Lixa Filgueiras, em 1958. A Escola será então um espaço coletivo com uma forte atividade cultural dinamizada pelo Centro de Estudos de Arquitetura e Urbanismo que realiza conferências, exposições e publicações. Esta dinâmica leva os professores e alunos do Porto a participar nos encontros internacionais, desde os CIAM, a UIA ou a Bienal de São Paulo.

A formação no Porto não promove só as capacidades artísticas e técnicas, mas desenvolve também a consciência crítica e social, apoiada numa forte formação teórica. Esta abordagem irá promover, entre outras, uma investigação sobre a arquitetura popular que será desenvolvida a diversos níveis, nomeadamente por Távora com a organização do "Inquérito às expressões e técnicas tradicionais portuguesas”, e por Filgueiras, na elaboração da sua tese (CODA), Urbanismo: um tema rural, ambos realizados em 1953. Mas o contributo de Távora e Filgueiras será exponenciado

540 ERNESTO N. ROGERS, A arquitetura moderna desde a geração dos mestres, Porto, Edições CIAM Porto, 1960, p.16-17. Tradução Sílvia Viana de Lima,

541 Humanismo Moderno é definido por Corliss Lamont (1902-1995), em The Philosophy of Humanism (1949), como "uma filosofia naturalista que rejeita todo supernaturalismo e repousa basicamente sobre a razão e a ciência, sobre a democracia e a compaixão humana". Lamont estudou em Oxford com Julian Huxley, primeiro diretor da UNESCO, e em Columbia com John Dewey, fundador da pedagogia moderna e do método "learning by doing". 
a partir do longo trabalho de investigação realizado no Inquérito à Arquitetura Regional Portuguesa (IARP), onde dirigiram, com estudantes da Escola, a equipas do Norte de Portugal. Este estudo sobre as razões arquitetónicas, sociais, culturais e geográficas da arquitetura popular iria constituir a base para pensar outras formas de habitar, através de uma proposta apresentada pelo grupo CIAM Porto ao CIAM X.

\section{CIAM Porto: debate sobre o habitat}

Segundo o presidente dos CIAM, Josep Lluis Sert, o principal objetivo do congresso de Dubrovnik seria o de promover uma nova abordagem para a estrutura do habitat humano. Para perseguir esse objetivo, foram apresentadas e discutidas em Dubrovnik trinta e cinco "grelhas". O grupo Português contribuiu com um projeto para uma comunidade agrícola, desenvolvido por Alfredo Viana de Lima, Fernando Távora e Octávio Lixa Filgueiras, com a colaboração de Arnaldo Araújo e Carlos Carvalho Dias. O projeto, intitulado "Habitat Rural. Nouvelle Communauté Agricole" deveria ser implantado numa área rural no nordeste de Portugal, integrada na zona II do IARP, coordenado pela equipa de Filgueiras. (Fig.1)

O projeto, apresentado em Dubrovnik por Viana de Lima e Távora, foi desenvolvido para uma comunidade de quarenta famílias, que era o tamanho médio das comunidades típicas da região. Essas comunidades também foram a referência para o traçado urbano do projeto, implantado ao longo das duas margens de um pequeno rio. De acordo com o texto enviado ao Congresso, a equipa Portuguesa argumenta que no seu projeto "foram adotados um traçado e uma composição muito simples, muito naturais, admitindo, caso necessário, um crescimento fácil da aglomeração." 542

A opção do grupo Português para apresentar uma comunidade agrícola no CIAM 10, destaca a sua preocupação em discutir a escala de um aglomerado rural como uma outra possibilidade de utilização dos princípios de desenho urbano do movimento moderno. De facto, na descrição do

542 CIAM-PORTUGAL, "X Congresso CIAM", em Arquitetura, n. ${ }^{\circ}$ 64, 1959, p. 23. 
projeto, o grupo afirma que o seu plano pode contribuir para a Carta do Habitat, reafirmando "a importância do Habitat rural, que os CIAM não podem ignorar se pretendem que as suas propostas sejam realmente universais" 543 . Ou seja, o grupo pretende demonstrar que os princípios do CIAM não podem ser apenas relacionados com as grandes cidades e com metrópole, mas também com as pequenas comunidades esquecidas pela abordagem heróica de geração entre guerras do CIAM.

$\mathrm{Na}$ verdade, este projeto revela uma tentativa de conciliar os princípios do CIAM entre guerras com a nova abordagem defendida pelo TEAM 10. Por um lado, quanto à estrutura urbana, o projeto é influenciado pela ideia de zoneamento, com a separação habitação, trabalho, e áreas de lazer bem definida, criando um sistema servido por uma rede de circulação, que articula os diversos setores. Por outro lado, o grupo é crítico da ideia moderna de autonomia disciplinar, e do papel heróico do arquiteto como autor de uma obra de arte total (gesamtkunstwerk). Eles argumentam que:

"A posição do arquiteto que não é mais o ditador que impõe a sua própria forma, mas o homem natural, simples, humilde, que se dedica aos problemas dos seus semelhantes não para se servir, mas para os servir, criando assim uma obra talvez anónima mas apesar de tudo intensamente vivida." 544

O grupo tenta demonstrar esta perspetiva através do uso de referências vernaculares no seu projeto. De fato, o projeto revela uma ambição deliberada de traduzir referências vernaculares numa linguagem moderna, por exemplo, na organização da unidade habitacional, na tecnologia de construção e na conceção dos volumes. Além disso, destacaram também o caráter evolutivo do projeto. De acordo com a descrição da "Grelha", a planta das habitações "permite uma grande variedade de tipos adaptáveis ao crescimento do aglomerado familiar, o qual poderia, por si próprio,

\footnotetext{
543 Ibidem, p. 24.
}

544 Idem. 
tomar a iniciativa da realização dos trabalhos indispensáveis para adotar [sic] a sua casa às necessidades do momento" 545 .

Para além da questão vernacular, o diálogo com as populações locais e principalmente com os futuros ocupantes através de um embrionário processo participativo com os utilizadores ganha nesta abordagem especial destaque, bem patente no desejo de "uma colaboração franca e permanente de todos os homens nas obras de arquitetura e de urbanismo, colaboração que lhes dá o direito de dizer a minha casa, a minha aldeia"546. Assim, o CIAM Porto revela o seu envolvimento na adoção de uma abordagem mais humanista à habitação e ao urbanismo, onde a variedade é elogiada em vez da uniformidade, e a espontaniedade é valorizada em vez do determinsmo idealista.

\section{Para um Humanismo Social}

Assim, podemos considerar que o humanismo clássico e o ensino moderno de Carlos Ramos deram a Távora e a Filgueiras as competências metodológicas para participar neste debate dos CIAM sobre a abordagem humanista ao habitat. O resultado desta formação é precisamente o projeto aqui apresentado mas também, num tempo mais longo, uma renovação do ensino da arquitetura em direção a um "novo humanismo".

Távora, que participou em Otterlo e Raymount, reivindicou uma “organização do espaço", "à escala do homem"547, enquanto Filgueiras defendeu a Função Social do Arquiteto argumentando que o "arquiteto, para realizar-se tem de saber fazer e, ao mesmo tempo conhecer as coisas, e o homem, e o mundo e a vida (...)"548.

Esta pedagogia é ilustrada pela disciplina, Arquitetura Analítica, lecionada por Filgueiras, ao longo da década de 60 através de um exercício

545 Idem.

546 Idem.

547 FERNANDO TÁVORA, Da Organização do Espaço, Porto, FAUP, 1996, p.14 (1962)

548 OCTÁvio LIXA FILGUeIRAS, Função Social do Arquiteto, Porto, FAUP, 1985, p.16 (1962) 
escolar denominado "Inquéritos Urbanos". Com um método de análise apoiado no desenho e na fotografia, os alunos estudaram a habitação popular urbana nos centros históricos (Fig. 2). O objetivo dos exercícios era conhecer o modo de habitar destas comunidades para melhor compreender e intervir.

O interesse de Filgueiras pela perspetiva humanista é ancorado tanto na The Architectural Review, especialmente a rubrica Townscape de Gordon Cullen e nos artigos de Rayner Banham, como nas ideias de Lúcio Costa, apresentadas na Escola do Porto, em 1961 na palestra Um novo humanismo científico e tecnológico. É também neste período que Filgueiras consolida as suas ideias com a tese Da Função Social do Arquiteto. Para uma teoria da responsabilidade numa época de encruzilhada, de 1962. Neste texto, Filgueiras enquadra o seu ponto de vista sobre a responsabilidade social do arquiteto com referência a Ernesto Rogers e Lúcio Costa, mas também a Alberti e Wittkower. Assim, denomina a sua perspetiva de "anti-lápis-maravilhoso" e explica, citando Rogers: "o arquiteto não é um elegante elaborador de formas de variados gostos, mas antes um moralista cuja tarefa é aumentar a alegria da vida e dela extrair os símbolos necessários para lhe dar forma" 549 .

Neste livro, Filgueiras entra em diálogo com Wittkower, destacando a importância do seu livro Architectural Principles para uma nova interpretação científica da Natureza, promovida pelos artistas do Renascimento. Contudo, Filgueiras considera os princípios arquitetónicos renascentistas como ecléticos e regressivos, tendo "a marca da aculturação proveniente do conúbio impossível entre dois mundos antagónicos, e muito principalmente, a adoção dum vocabulário cheio de compromissos com um mundo já distante" 550

Esta declaração clarifica a crítica de Filgueiras ao humanismo renascentista, "essa cosmogonia abstrata que não penetra na compreensão das pessoas, o que, até agora, só pode apreender a grandiosidade mundana de formas." Ele reconhece a importância de Alberti e seus colegas do

\footnotetext{
549 Apud FILGUEIRAS, 96.

550 OCTÁVIO LIXA FILGUEIRAS, Função Social do Arquiteto, pp.49-50.
} 
Renascimento em sistematizar o conhecimento, mas ele argumenta que, agora, o arquiteto tem que rejeitar uma certa ideia de autonomia disciplinar para promover um maior envolvimento da disciplina com o real. Assim, tanto o projeto apresentado pelo grupo CIAM/Porto em Dubrovnik, como as experiências pedagógicas posteriores de Távora e Filgueiras na Escola do Porto ilustram uma tentativa de analisar criticamente Alberti e o humanismo renascentista, com um novo e emergente humanismo social, que reconhece a importância de uma abordagem platónica, mas é orientado para promover um maior envolvimento social.

Nota:

Este artigo é parte do projeto "Alberti Digital" financiado pela Fundação para a Ciência e Tecnologia (FCT), COMPETE/FEDER, Portugal, e alojado no CES da Universidade de Coimbra (PTDC/AUR-AQI/108274/2008). O projeto foi coordenado por Mário Krüger. Gonçalo Canto Moniz e Nelson Mota foram investigadores do projeto. Nelson Mota desenvolveu a investigação no âmbito da bolsa de doutoramento da FCT (SFRH/BD/60298/2009). 


\section{Imagens}

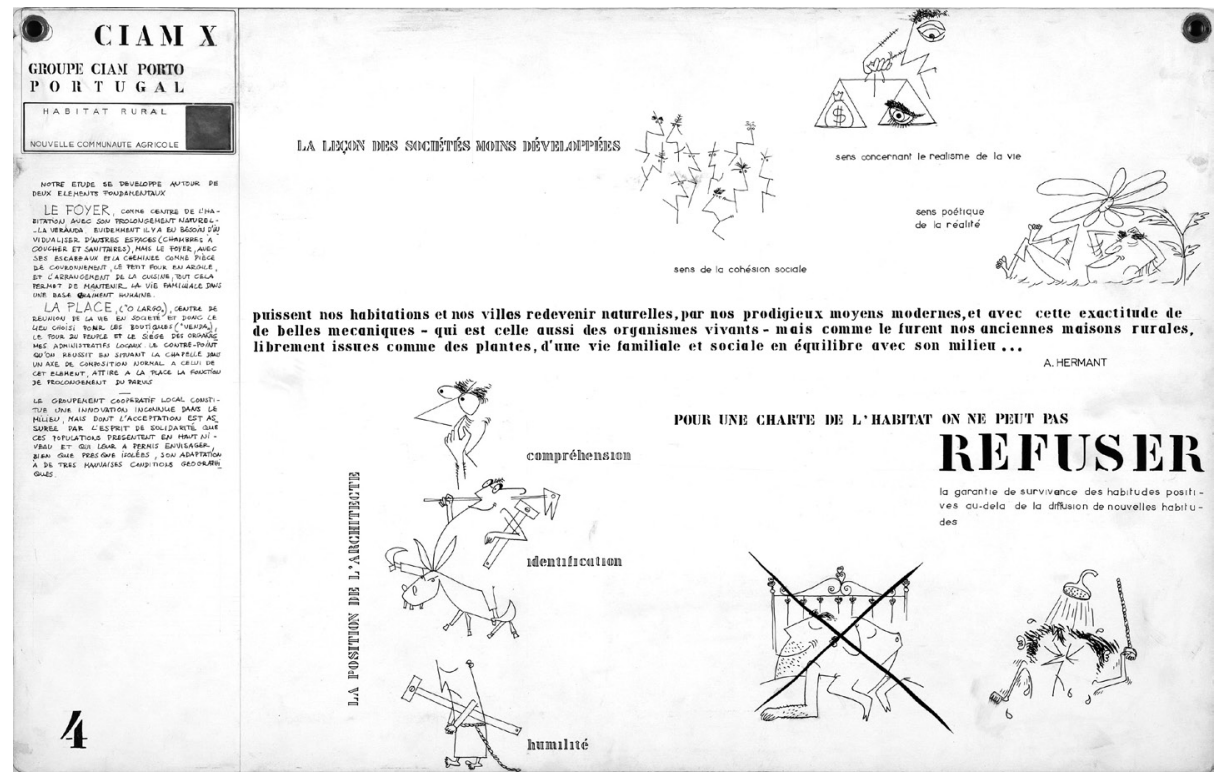

Fig. 1 - GROUP CIAM Porto - Portugal. "Habitat Rural" - Painel 4 do projeto apresentado no Congresso CIAM 10, 1956. Fonte: CDUA - FAUP.

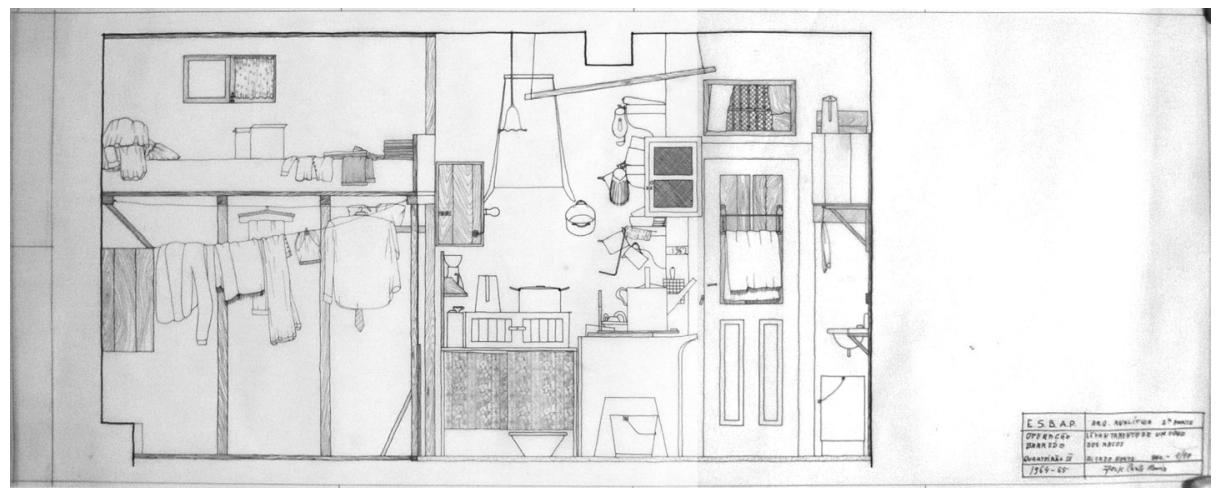

Fig. 2 - JORGE CANTO MONIZ, Operação Barredo - Quarteirão IV, Levantamento de um fogo, Arquitetura Analítica, ESBAP, 1964-65. Arquivo CDUA-FAUP. ARQAN1-009-PR10-13-3 